\title{
Research on the drilling winch control system for clean sampling of Antarctic Subglacial Lakes
}

\author{
Chunbao Liu ${ }^{1 *}$ and Sheng Zhang ${ }^{1}$ \\ 1. Applied Technology College of Jilin University \\ Mailing address: Applied Technology College of Jilin University, No.5372, Nanhu Boulevard, Changchun 130041, China
}

\begin{abstract}
Antarctica, with a large number of ice sheets, is among the last unexplored places on Earth. The subglacial lakes beneath these ice sheets have been isolated from the outside world for up to 35 million years, containing a diverse group of marine organisms and other materials. Its unique hydrological environment provides insights regarding microbial evolution and past climates on Earth, which have become central to interpreting the process of landscape evolution and assessments of possible future climate change. Clean sampling of subglacial lake water without introducing surface biological or other type of contamination has long been a goal of the international scientific community. The overlying ice thickness can reach thousands of meters and in conventional deep ice drilling, drilling fluids are employed while the boreholes exposed to the atmosphere. The only method for penetration is thermal drilling with the rate proportional to the vertical diameter of the drilling rig, which requires the drill body to be as thin as possible. The melted ice/water in the upper borehole will refreeze immediately once penetrating into the ice layers. Cables, thereby, need to be configured inside the drilling rig since separate cables from the external surface are not applicable in such cases. The drill rig comprises the motor-driven winch, outer surface heating system, control system as well as sampling system, totaling $600 \mathrm{~kg}$ in weight. Gear reducers are required during the cable lowering/lifting operations with a maximum outer diameter of the winch of $140 \mathrm{~mm}$ and a high-precision automatic synchronization between the reducers and cable lowering/lifting system is required. An automatic tension sensor along with a winch control system is designed to realize thee automatic synchronization between the gear reducers and the cable lowering/lifting system through servo control.
\end{abstract}

\section{Introduction}

Antarctica, with a large number of ice sheets, is among the last unexplored geographical environment on Earth so far. In 1961, A.P. Kapitsa proved the existence of liquid beneath the central regions of the ice sheets ${ }^{[1]}$ and it has been verified that the underlying subglacial lakes have been isolated from the outside world for up to tens of millions of years or even longer. Hence, it is possible to contain a diverse group of marine organisms and other materials. The analysis of these materials can be effectively helpful and extremely valuable to our understanding of the process of landscape evolution and assessments of possible future climate changes. A critical issue on sampling qualified subglacial lake water is to prevent from surface microbial and material contaminations. It is of great significance to explore the physical and chemical characteristics of subglacial water system under conditions of high pressure, low temperature, low nutrition and dark environment by means of the corresponding analyses of the clean samples. Not only is it crucial for revealing the formation mechanism and dynamics of subglacial lakes and Antarctic ice sheets, but also for investigating the material equilibrium patterns.

At present, scientists from different countries are devoting themselves to clean sampling technology for Antarctic subglacial lakes as the practical realization still remains a worldwide puzzle. Conventional drilling rigs are no longer applicable under this circumstances because of the need of drilling liquids and the uncovered boreholes. The only method for penetration is thermal drilling, whose rate is proportional to the vertical diameter of the drilling rig. Thus, the drill body is supposed to be as thin as possible in order to meet the isolation requirement. Once entering the ice layers, the melted ice/water in the upper borehole will refreeze immediately as the drilling rig moving down. Neither separate cables or other type of power supply can be provided from external surface, requiring the power

*Corresponding author: Chunbao Liu, E-mail: cbliu@jlu.edu.cn 
supply system along with the cables be configured inside the drilling rig. Figure 1 shows the schematic of the drilling process. The drilling rig consists of the motor-driven winch, outer surface heating system, control system and sampling system. Most of them are designed to work under the external pressure of $20 \mathrm{Mpa}$ at least. leading to the total weight of the system up to $600 \mathrm{~kg}$. Gear reducers must be used during the cable lowering/lifting operations. The maximum outer diameter of the winch should not exceed $140 \mathrm{~mm}$ due to space constraints. Reducers and cable lowering/lifting system are managed to coordinate with each other for a high-precision automatic synchronization. An automatic tension sensor and a winch control system are designed to realize the automatic synchronization between the gear reducers and the cable lowering/lifting system through servo control.

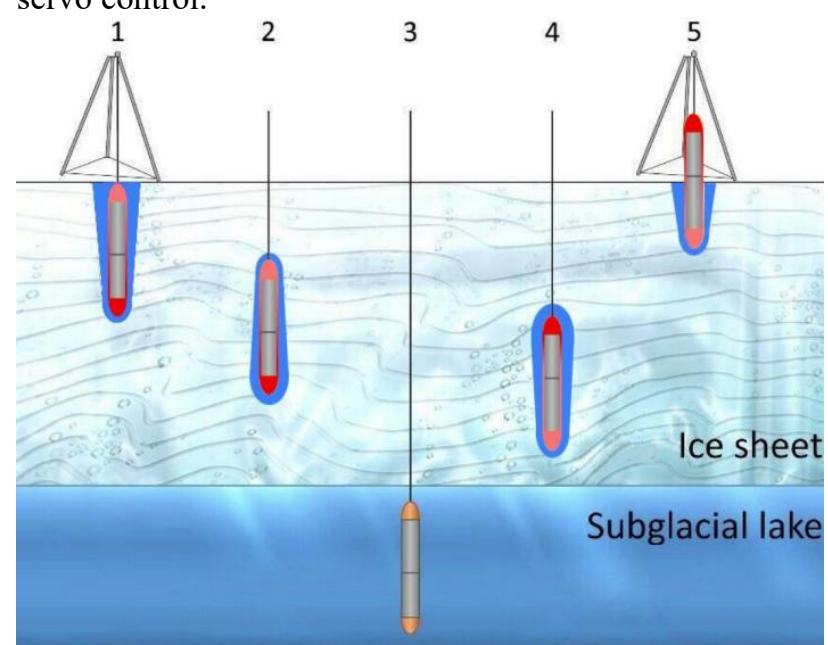

Figure 1. Schematic of clean subglacial lake drilling system.

\section{Materials and Methods}

\subsection{Winch system design}

Figure 2 shows the structure of the drilling winch system. The winch system is responsible for all the lowering-lifting operations and electricity transmission of the entire drilling rig. Main components include the driving unit, pressure chamber of the control system, sensor chamber and cable traverse chamber.

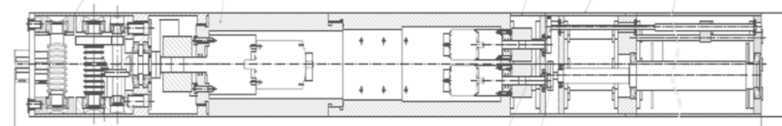

Figure 2. Schematic of the winch system.

\subsubsection{Cable traverse chamber}

As illustrated in Figure 3, the cable traverse chamber is composed of the drum, ball screw, lead screw and slider with the guide pulley. To avoid cable disorder during the cable winding process, the lead screw drives the slider to do reciprocating motion along the ball screw in pace with cable winding.

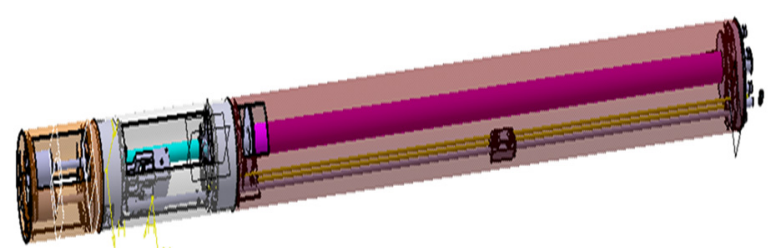

Figure 3. Schematic of cable traverse chamber.

\subsubsection{Driving chamber unit}

The driving chamber unit is equipped with groups of bevel gears and spur gears. The output torque of motor chamber is increased by a two-stage transmission of the gear groups so as to reduce the cable tension exerted on the drum. The structure is demonstrated in Figure 4.

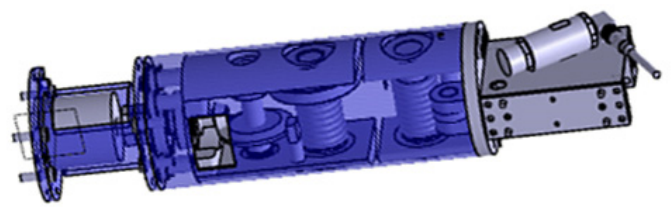

Figure 4. The driving chamber unit.

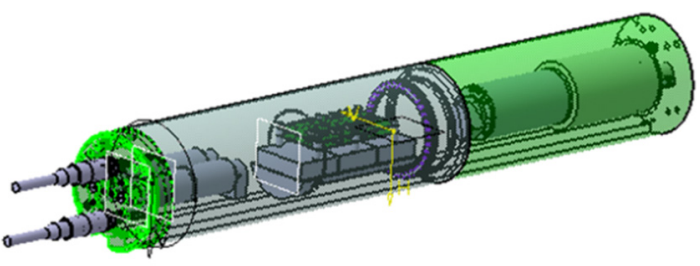

Figure 5. The pressure chamber of the control system.

\subsubsection{Calculation and analysis of the driving torque}

Torque of the driving bevel gear:

where $\mathrm{n} 1$ is the reduction ratio of the gear reducer, is the gear reducer efficiency, is the coupler efficiency, is the transmission efficiency of tapered roller bearing.

Assuming:

$$
\begin{gathered}
T_{\text {moter }}=0.742 N m \\
\mathrm{n}_{1}=93, \eta_{1}=0.7, \eta_{2}=0.99, \eta_{3}=0.98,
\end{gathered}
$$
we obtain:

$$
T_{\text {driving bevelgear }}=46.86 \mathrm{Nm} \text {. }
$$

Torque of the gear shaft:

$$
T_{\text {gearshaft }}=T_{\text {driving bevelgear }} n_{2} \eta_{3} \eta_{4}
$$

where $\mathrm{n}_{2}$ is the speed ratio of bevel gears and $\eta_{4}$ is the transmission efficiency of the bevel gear.

Assuming $n_{2}=2.67, \eta_{3}=0.98, \eta_{4}=0.95$, we obtain that:

$$
T_{\text {gear shaft }}=116 \mathrm{Nm} \text {. }
$$

Torque of driving grooved wheel shaft:

$$
T_{\text {driving grooved wheelshaft }}=T_{\text {gearshaft }} n_{3} \eta_{3} \eta_{5}
$$

where $\mathrm{n}_{3}$ is the speed ratio of bevel gears and $\eta_{5}$ is the transmission efficiency of cylindrical gear. 
Assuming $n_{3}=2.29, \eta_{3}=0.98, \eta_{5}=0.98$, we obtain that:

$$
T_{\text {driving grooved wheel shaft }}=256 \mathrm{Nm} \text {. }
$$

Thus, the torque of the driving grooved wheel shaft meets the minimum requirement of $10000 \times 0.02=200$ $\mathrm{Nm}$.

\subsubsection{Analysis of the cable traverse torque}

$$
T_{\text {driving gears of the drum }}=T_{\text {moter }} n_{1} \eta_{1} \eta_{2} \eta_{6}
$$

where $n_{1}$ is the reduction ratio of the reducer, $\eta_{1}$ is the reducer efficiency, $\eta_{2}$ is the coupler efficiency and $\eta_{6}$ is the transmission efficiency of ball bearing. Assuming:

$$
\begin{gathered}
T_{\text {moter }}=0.19 \mathrm{Nm} \\
n_{1}=113, \eta_{1}=0.72, \eta_{2}=0.99, \eta_{6}=0.99,
\end{gathered}
$$

we obtain that:

$$
\begin{gathered}
T_{\text {drum pinion }}=15.3 \mathrm{Nm} \\
T_{\text {driven gears of the drum }}=T_{\text {driving gears of the drum }} n_{2} \eta_{3} \eta_{5}
\end{gathered}
$$

where $n_{2}$ is the speed ratio of the grooved wheel, $\eta_{5}$ is the transmission efficiency of the straight-toothed spur gears.

Assuming $n_{2}=30 / 17, \eta_{5}=0.98$, we obtain:

$$
T_{\text {drivengears of the drum }}=26.7 \mathrm{Nm}
$$

Thus, the torque of driven gears of the drum meets the minimum requirement of $123 \times 0.045=5.5 \mathrm{Nm}$.

\subsection{Tension sensor design}

The tension sensor is design for the control of cable tension, which can be normally ensured by the control functions of the drum and driving motors based on experimental data. However, the elastic deformation caused by temperature vibration or deviation by cable slipping may cause accumulated errors in winding process or sudden changes of tension. If so, compensatory adjustments have to be made to the rotational speeds of both driving motor and drum motor in time. Figure 6-8 give the schematic diagram, the layout picture and the internal structure of the pressure sensor, respectively.

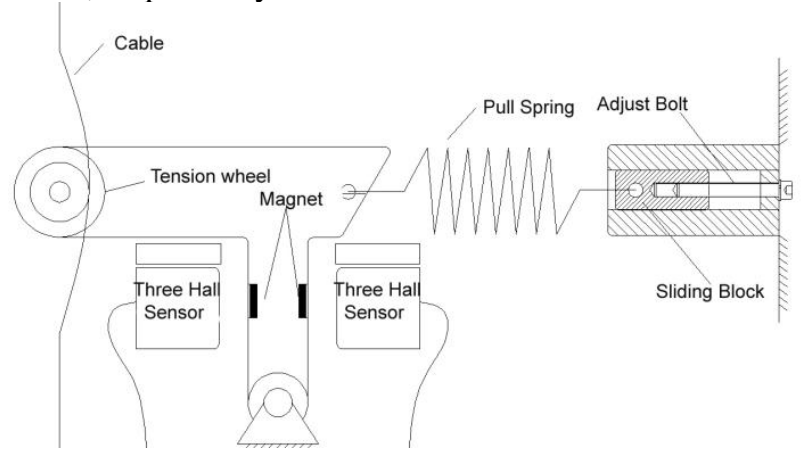

Figure 6. Schematic of the tension sensor.

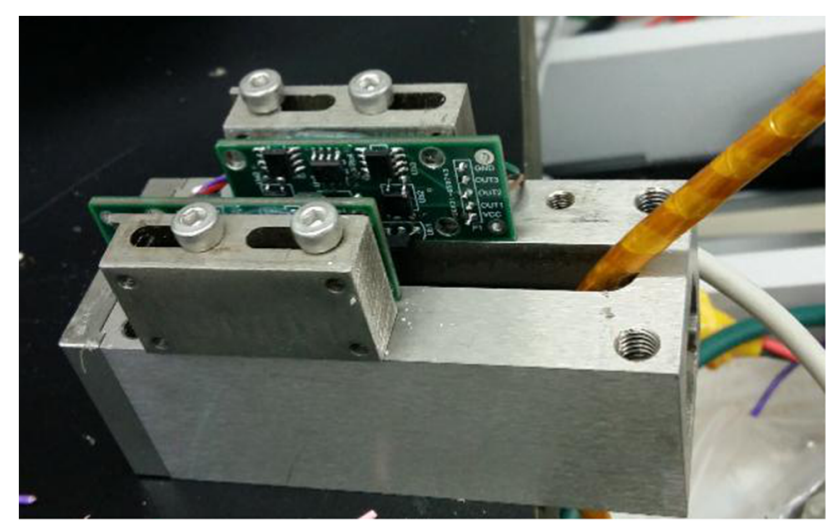

Figure 7. Picture of the tension sensor.

A tension adjustment screw is equipped to move the slider connecting to the tension spring. Thus, the tensile force exerted on the "A-frame", which is equivalent to the cable tension, is regulated accordingly. Under standard tension, the "A-frame" is supposed to be located in the middle of the two Hall effect sensors and keep the permanent magnets from the Hall sensors, when no output signals being observed. In fact, the "A-frame" will remain in the middle as long as the driving and drum motor function well without accumulating errors or sudden slips ("bucking"). As a result of the tension spring, the frame will rotate to the right when a deviation occurs with the cable being slack. If the cable is too slack and the rotational angle can reach 90 degrees, the Hall sensor on the right will be triggered and transmit signals to the slave control board. An interrupt program is activated subsequently and raise the rotational speed of the drum motor in order to tighten the cable, making the frame rotate back to the middle positon. If the rotational speed of driving motor is too slow, the "A-frame" will rotate to the right on account of the cable being too tightened. The Hall effect sensor on the left will be triggered and transmit signals to the slave control board to activate the interrupt program. The cable will be loosened as the rotational speed of the drum motor decreased, thereby making the "A-frame" back in the middle.

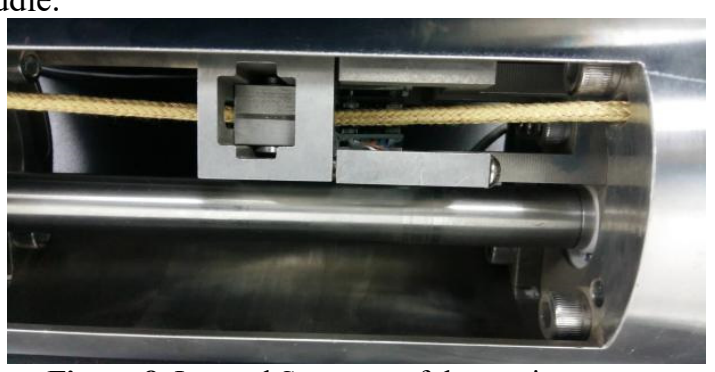

Figure 8. Internal Structure of the tension sensor.

\subsection{Control circuit design}

The schematic of the control circuit is shown in Figure 9. There are two CPU boards embedded in the system with one of them working alternatively while the other serving as a real-time online redundancy backup. Board 2 is initially activated and will sent two signals to board 1 : enable 2(non-stop) and work2 (once per second). If the normalcy of them are verified, board 1 will connect the direction of the servo controller and the end of pulse 
controller to board 2 through Ke1、Ks1、Kq1 and board 2 will take over control. If board 2 breaks down, Ke1、Ks1 $\mathrm{Kq} 1$ will be disconnected and the direction of the servo controller together with the end of pulse controller will be switched back to board 1, thereby stopping board 2 from control.

The encoder signal is directly sent into the servo controller via the interface of board 1. Both pulse and direction method are used by the servo controller and control signals are divide into three groups: the enable signal group, the direction signal group and the motion pulse signal group. The enable signals are controlled by board 2 and a normal working state signal will be sent to board 1 meanwhile. In normal cases, the working information of the winch are recorded by both 1 and board 2 simultaneously as each function - monitoring, recording as well as storage running smoothly. Once board 1 receives the normal working state signal from board 2, it will connect the direction signal and the motion pulse signal of the servo controller to the output of board 2 via the change signal. Then the winch will be controlled by board 2. With respect to the abnormal conditions of board 2, the enabling control of the servo controller will be released, followed by the disappearance of the normal working state signal of board 2. When detected by board 1, board 1 will then connect the direction signal together with the motion pulse signal of the servo controller to the output via the change signal. The servo controller will be controlled by board 1 afterwards. Board 2 will keep working despite of the failure of board 1 during the operations, since board 1 will released the control over board 2, allowing the ladder to function normally.

The cutter load sensor is intended to control the rotating direction of the driving motor. If the cutter load exceeds the prescribed value, the lowering speed should be accelerated. Conversely, if the cutter load is smaller than the prescribed value, it is indicated that the drill is about to touch the bottom and the cable lowering speed should be reduced in case of drill leaning.

The running parameters of the driving motor calculated by the CPU board according to the measured cutter load information and then sent to the servo controller of the driving motor. The cable, driven by the grooved wheel, starts to move while the cable tension information, measured by the tension sensor, is sent back to the CPU board. The running parameters of lead screwmotor as well as drum motor are computed and then sent to their servo controllers, respectively. Hence, the synchronization of the three servo controllers is realized, ensuring a uniform pattern of cable winding on the drum.

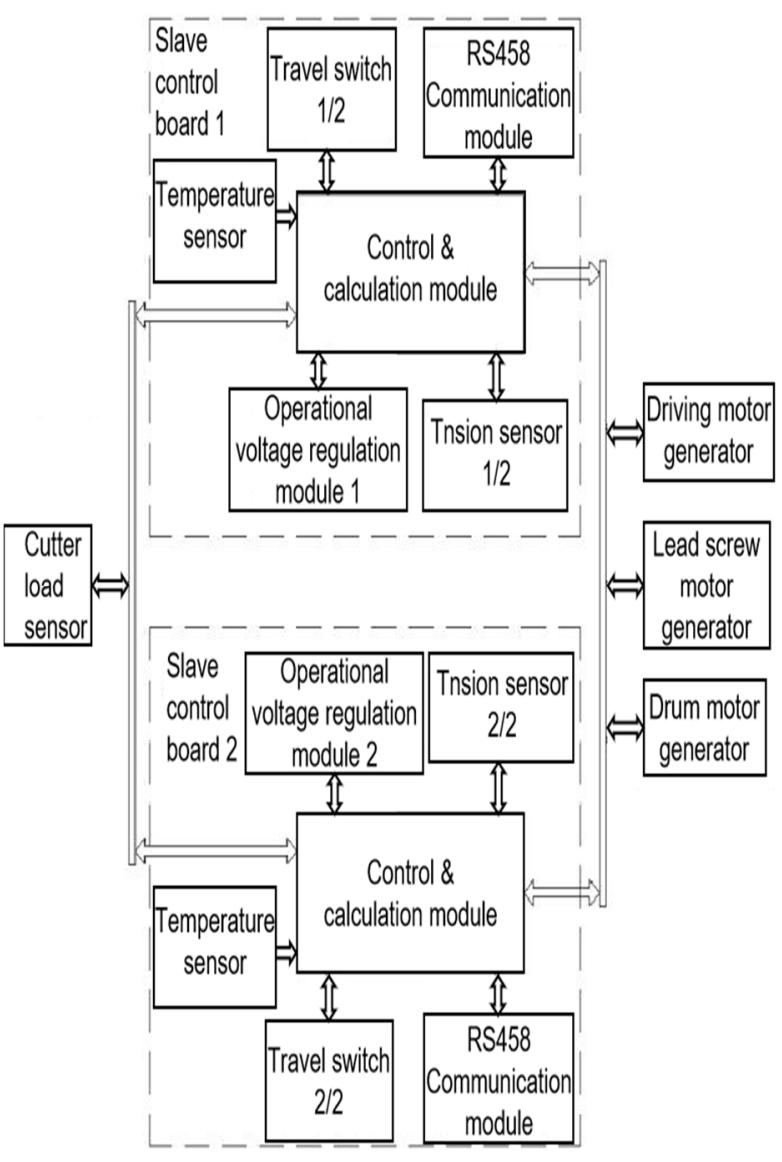

Figure 9. Schematic of the logic structure of the winch control system.

\subsection{Control flow design}

The first step is to conduct self-tests of the control system. Given the double backup control board in our system, the self-test will start with board 1 and has to be conducted twice. If the results are normal, board 2 is on standby and board 1 will be activated in coincidence. After the two self-tests of board 1 in the beginning the control program, only with abnormal results, can the control over board 2 be released to work with power. Figure 2 shows the logical schematic of each modules in the system. It is the cutter load sensor that controls and determines the entire winch. On one hand, an insufficient cutter load indicates the sampler lowering speed is faster than that of ice melting, resulting in leaning of the sampler. Besides, the entire control system will fail in the sense of a slack cable may cause slips of the reducer in the drive unit. On the other hand, an exceeding cutter load correspond to the overtight cable, will take the risk of damage or even breakage of cable. With respect to the cutter load sensor in our system, signals are transmitted via RS485 bus, thereby enabling an open access to the main and also the slave control board. The main control board will send instructions to each module according to running parameters derived from an integrated calculation with the cutter load information and other signals of the entire sampler. Meanwhile, instructions regarding lifting, lowering or stopping are sent to the winch alternately. Once received by the slave control 
board, an alternative circuit will operate in accordance with the control flow. Subsequently, instructions are sent to the three generators of driving motor, drum motor and lead screwmotor for their synchronization. The travel switch is used to record the layers of the drum and protect the travel of the lead screw. The tension sensor is used to compensate for the displacement during cable winding operations. The temperature sensor is used to monitor and control the environmental temperature of the driving chamber. The RS485 communication module is used to communicate with the main control board along with other related sensors. The operational voltage regulation module is used to control power supply to slave control bard 1 or 2 and make sure one of them function well.

After passing the self-tests, the program will stand by for further running instructions from the main control board or come into brakes holding state otherwise. The type of reactions needs to be determined when an instruction is received, which are divided into three type: lowering, lifting and other instructions. Lowering instructions mainly refer to the lowering direction and lifting speed. Following a lowering instruction, the cable elastic coefficient can be measured with the help of the observed cable temperature while the winding cable perimeter can be acquired by the cable layer information. Therefore, the lowering speed of cable and the step size of the driving motor can be obtained and being coded into control instructions of the generator before being sent to the driving motor generator. Specifically, the rotational angle information of the driving motor is the primary input for controlling the drum motor. Experimental tested parameters are outputted to the generator of drum motor with the help of PID algorithm. The drum meter is servo-controlled while the lead screw motor is follow-up controlled with distinct follow-up parameters in each layer. The main contents of lifting instructions include lifting and lifting speed. Following a lifting instruction, the cable elastic coefficient can be measured with the help of the observed cable temperature while the winding cable perimeter can be acquired by the cable layer information. Therefore, the lifting speed of cable and the step size of the driving motor can be obtained and being coded into control instructions of the generator before being sent to the driving motor generator. Specifically, the rotational angle information of the driving motor is the primary input for controlling the drum motor. Experimental tested parameters are outputted to the generator of drum motor with the help of PID algorithm. The drum meter is servo-controlled while the lead screw motor is follow-up controlled with distinct follow-up parameters in each layer. The flowcharts of the complete operation and the lowering/lifting subprogram of the winch are given in Figure 10 and Figure 11, respectively. The layer information of the drum is recorded by the travel switch, as shown in Figure 12.

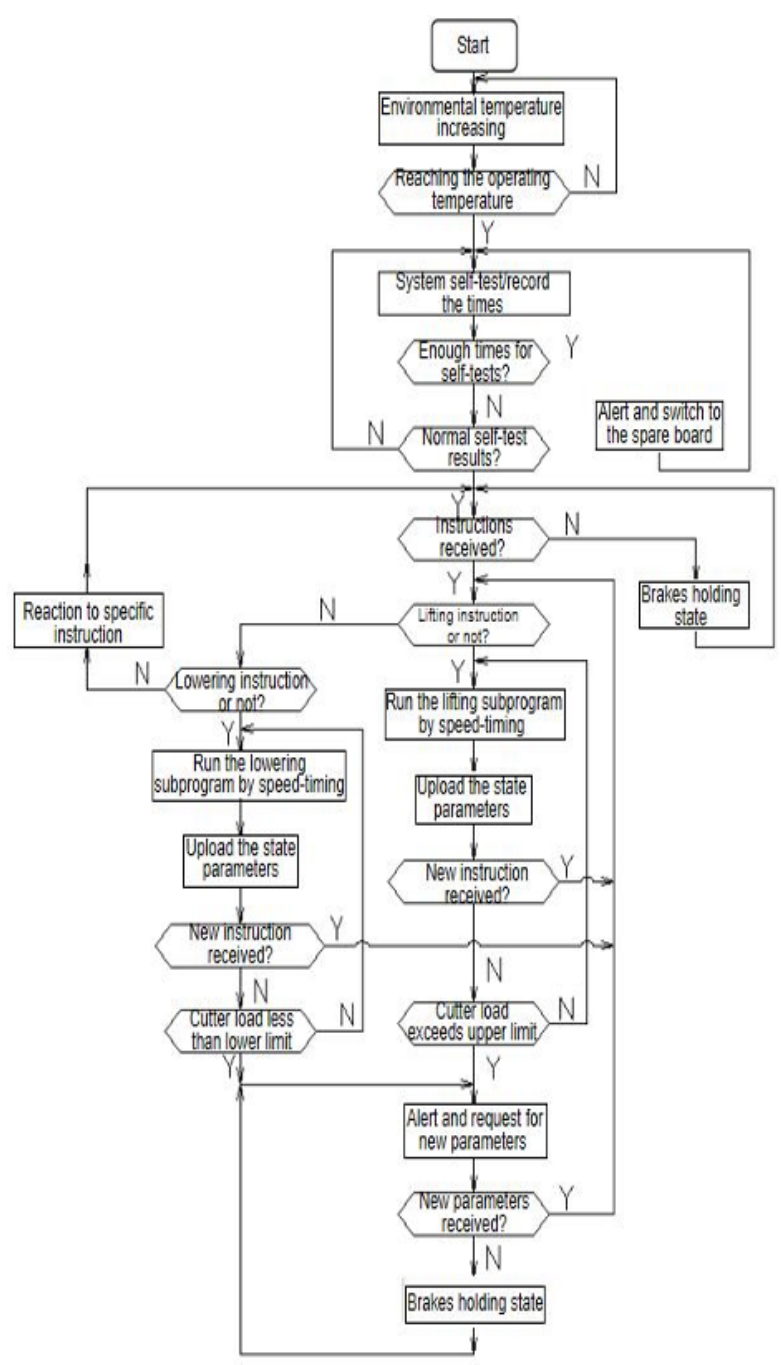

Figure 10. Main flowchart of the winch control. 


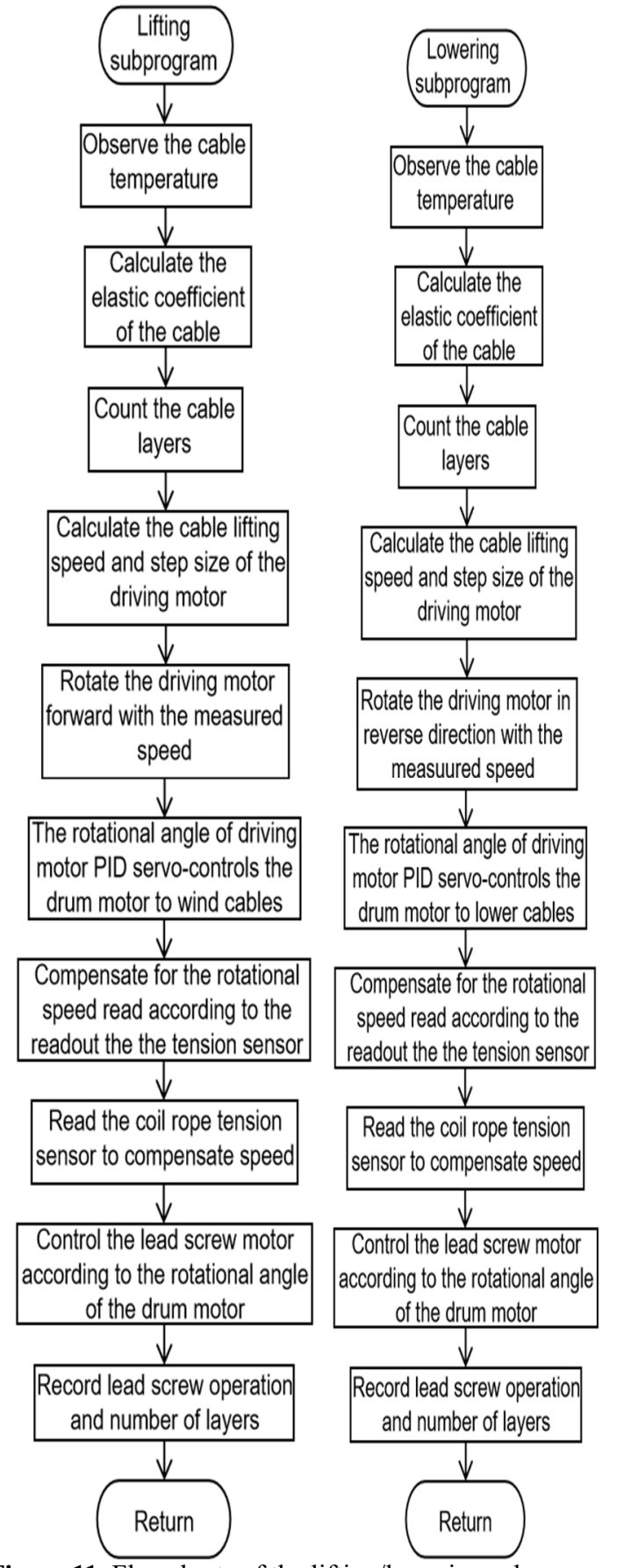

Figure 11. Flowcharts of the lifting/lowering subprogram.

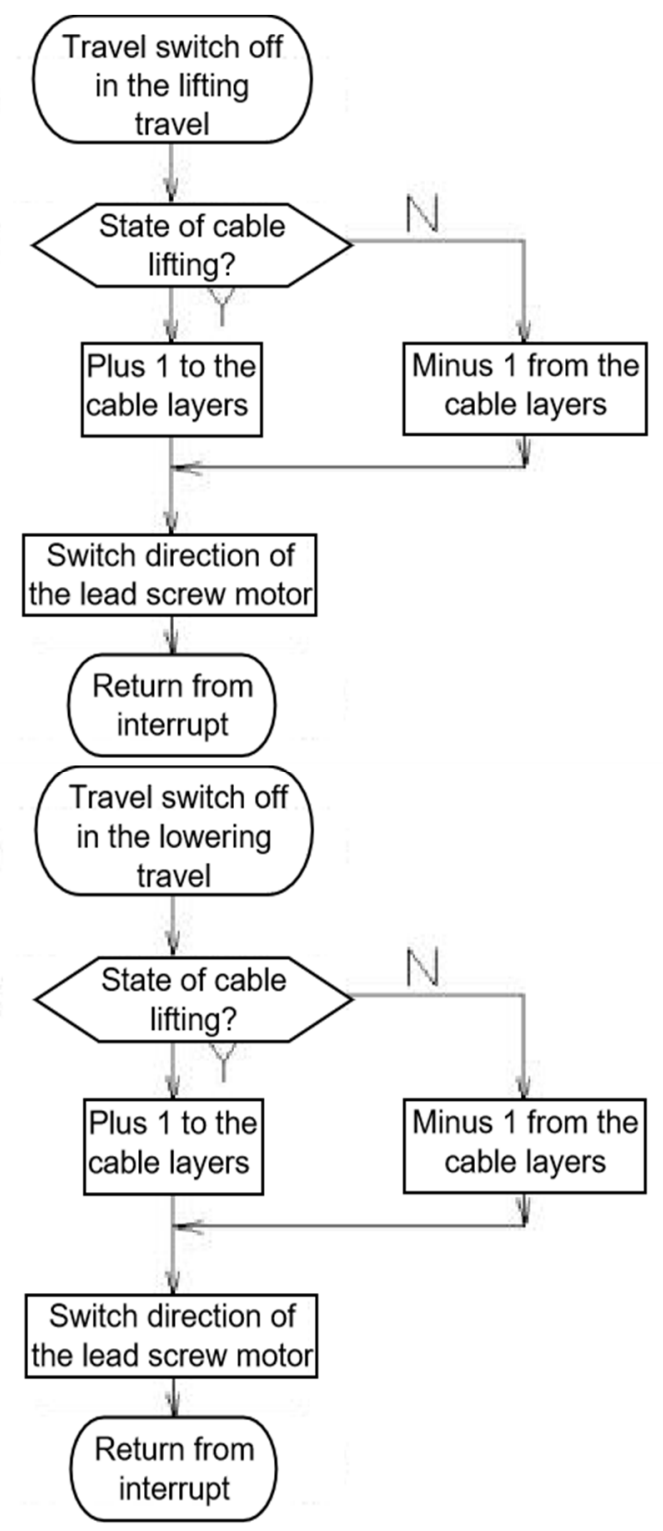

Figure 12. Interrupt subprogram of the travel switch.

\section{Results \& Discussion}

\subsection{Tests}

\subsubsection{Test on cable winding mechanism}

The purpose of this test is to analyze, verify and adjust the interactions between the drum, tension sensor and lead screw. The test device is shown in Figure 13.

By adjusting the weight of the load hanging at the end of the cable on the right side of the figure, the cable lowering/lifting operations in the driving unit can be imitated. The corresponding signals can make the lead screw and the drum to react synchronously. Figure 14 and Figure 15 show the effects of cables lowering/lifting in the first and fifth layer, respectively. 


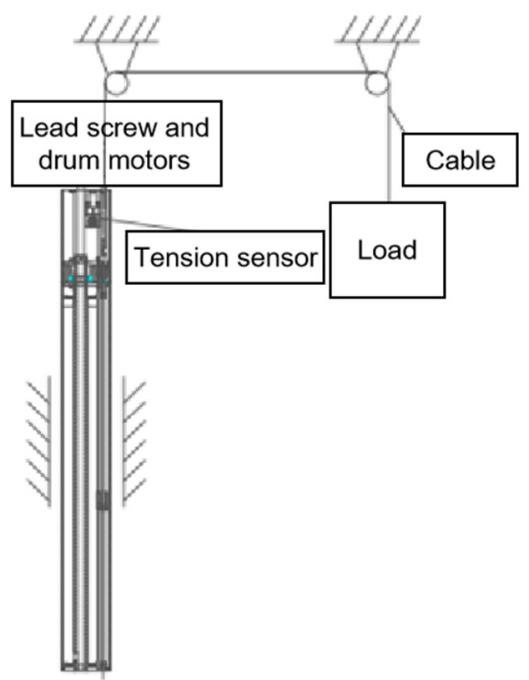

Figure 13. Schematic of cable winding mechanism test device.

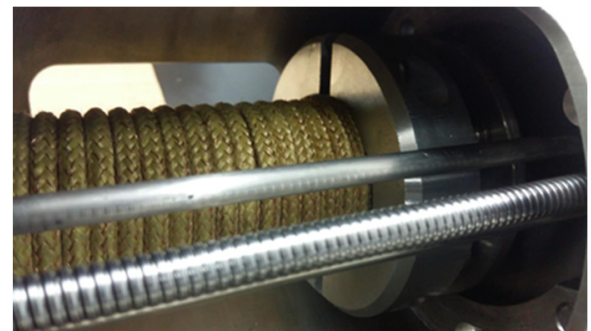

Figure 14. Layout of the winding cables on the drum in the first layer.

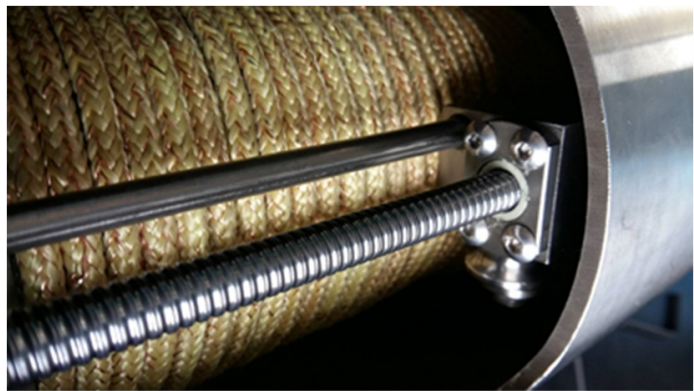

Figure 15. Layout of the winding cables on the drum in the fifth layer.

\subsubsection{Actuator test}

Figure 16 shows the schematic of the driving unit test device. The test is carried out to test the load capacity of the winch, the braking performance of the brake, the stability of the servo motor, the effect of cable winding as well as the reliability of the entire machine. The test results are shown in Table 1.

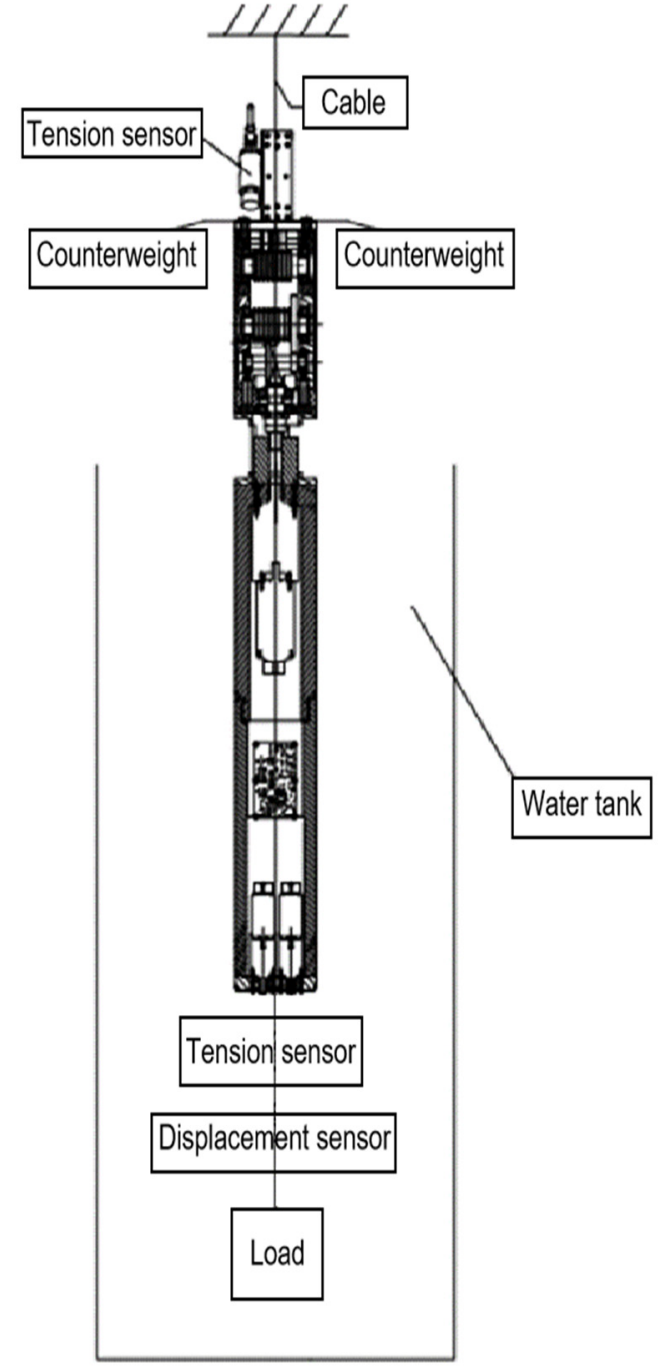

Figure 16. Schematic of the driving unit test device. 
Table 1. Test results of the driving unit.

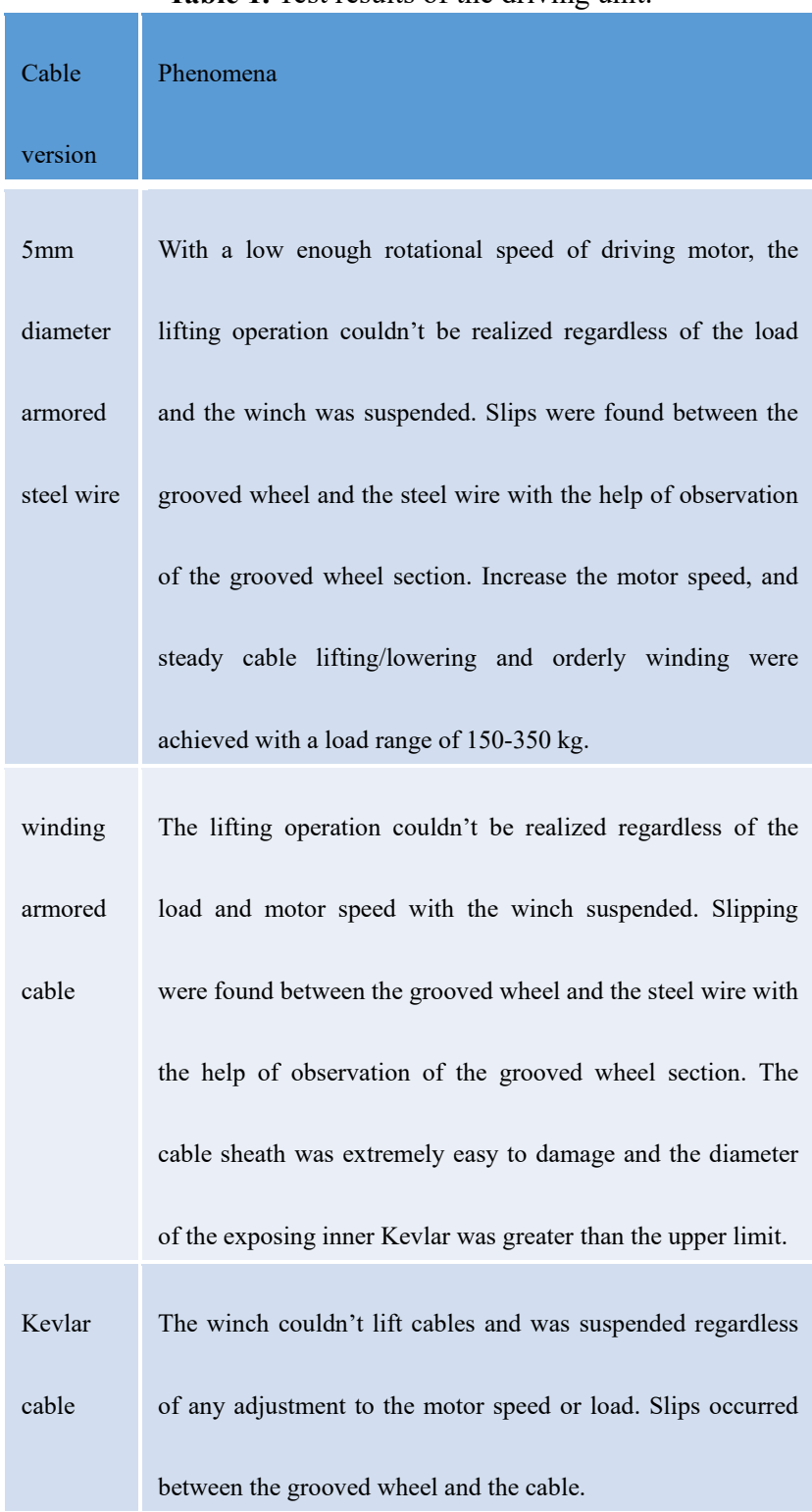

$5 \mathrm{~mm}$ The situation of the steel wire with sheath was similar to that

diameter of the cable. The winch couldn't lift cables and was suspended

steel wire regardless of any adjustment of the motor speed and load.

rope Slips occurred in the grooved wheel and cables.

armored With the load of $100 \mathrm{~kg}, 220 \mathrm{~kg}, 387 \mathrm{~kg}$, the control motor

extrusion managed to lowering/lifting smoothly in both forward and

cable reserve direction without observed slips in the grooved wheel

section. The cable armor was damaged with the exceeding diameter of about $6 \mathrm{~mm}$. Force-deformation of the cable resulted in the diameter ranging from 4.5 to $7 \mathrm{~mm}$.

\subsection{Analysis}

As shown in Figure 2, the test data were measured by the load test of the entire system. It is indicated that the maximum load for a single-driver grooved wheel without slips is $300 \mathrm{~kg}$ under the conditions of the new cable without waterlogging. The load decreased to $200 \mathrm{~kg}$ when testing a used cable with waterlogging, which cannot meet the $600 \mathrm{~kg}$ load requirement in practice.

A double-driver scheme was designed for the optimization of driving chamber. The test was conducted again and the load was greater than $720 \mathrm{~kg}$ except for the case of an old cable with waterlogging when the load was less than $200 \mathrm{~kg}$. The test results indicate that the system should adopt the scheme of double-driver driving chamber and its schematic is given in Figure 17.

Table 2. Data of the driving unit load test.

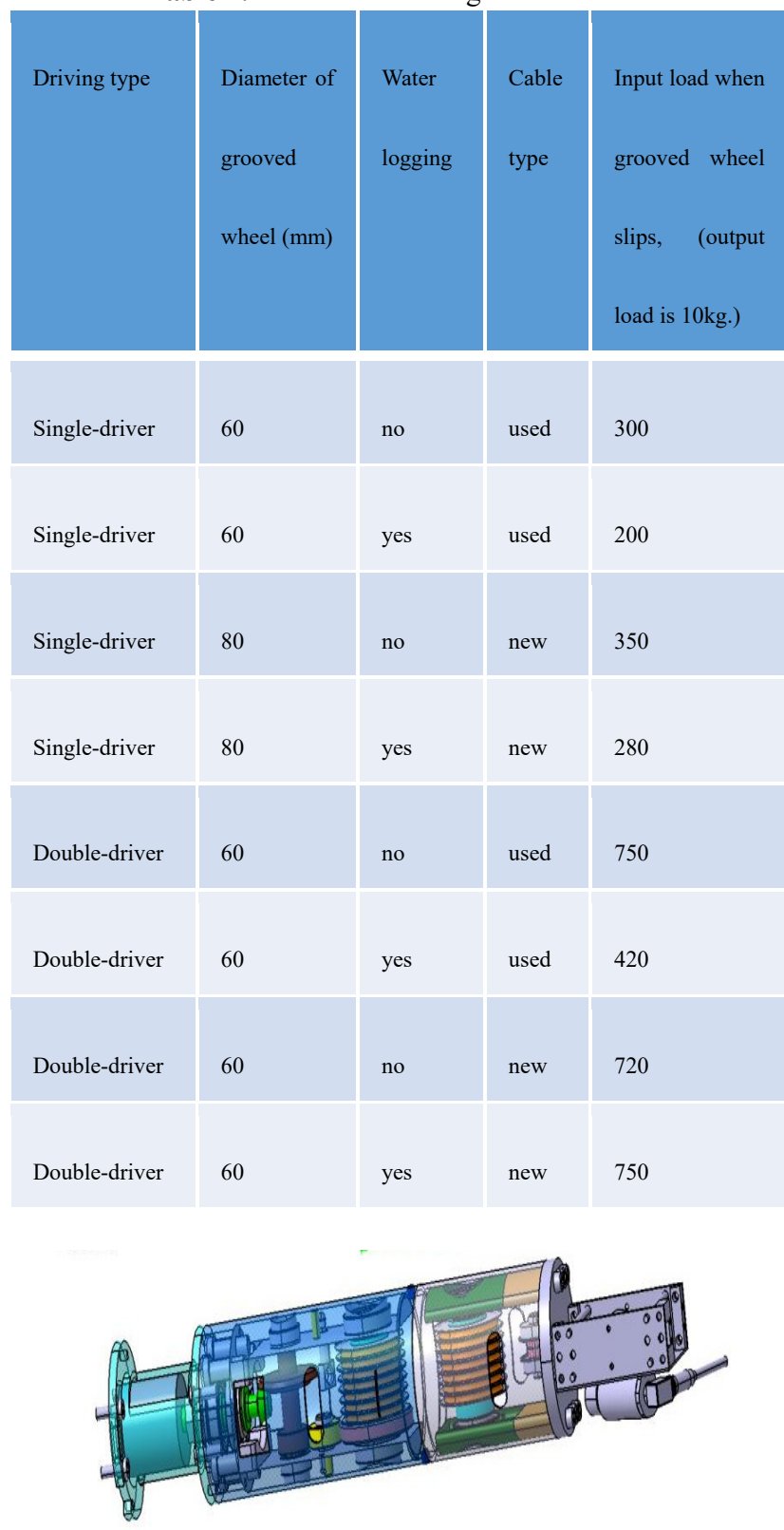

Figure 17. Schematic of the double-driver driving motor. 


\section{Conclusions}

Various schemes of the driving unit embedded in the winch system are compared and analyzed with regard to the actual drilling conditions of Antarctic subglacial lakes. An experimental bench is set up in order to find out the optimal solution based on tests. It is preliminarily determined that the scheme of multiple grooved wheel can satisfy with lowering and lifting requirement of the entire drilling tool.

\section{Acknowledgments}

This project comes from the national key research and development plan of China's Agenda 21 Management Center. Special Program Name: Marine environmental security, Project No. 2016yfc1400302. Project name: research and development of the clean drill sampling and observation system for Antarctic subglacial lakes. Thanks to all the support for the project.

\section{References}

1. Wright A, Siegert MJ. The identification and physiographical setting of Antarctic subglacial lakes: An update based on recent discoveries[J]. Geophysical Monograph, 192: 9-26 (2011)

2. Siegert M J, Priscu J C, Alekhina I A, et al. Antarctic subglacial lake exploration: first results and future plans $[\mathrm{J}]$. Philosophical Transactions, 374(2059):2014 0466. (2016)

3. Lukin V V, Vasiliev N I. Technological aspects of the final phase of drilling borehole $5 \mathrm{G}$ and unsealing Vostok Subglacial Lake, East Antarctica [J]. Annals of Glaciology, 55(65): 83-89 (2017)

4. Mikuvki J A, Lee P A, Ghosh D, et al. Subglacial Lake Whillans microbial biogeochemistry: a synthesis of current knowledge [J]. Philosophical Transactions of the Royal Society A: Mathematical, Physical and Engineering Sciences, 374(2059): 20140290. (2016)

5. Zhao Liang, theoretical research on several key parameters of RS485 bus [J].MCU and embedded system applications, 14(6): 14-17 (2014) 